\title{
Erratum to: Membership grade mining of mutually inverse fuzzy implication propositions
}

\author{
Xunwei Zhou ${ }^{1}$
}

Published online: 10 November 2016

(C) Springer International Publishing Switzerland 2016

\section{Erratum to: Granul. Comput.}

DOI 10.1007/s41066-016-0026-1

In the original publication of the article unfortunately a typesetting mistake occurred. In the second line of Eq. 5 " 1 -" is missing at the beginning. The correct equation reads:

$\mathrm{ss}= \begin{cases}0.5, & 0.5 \leq \text { intc } \leq 1 \quad \text { (neutral area) } \\ 1-\text { intc }, & 0 \leq \text { intc }<0.5 \quad \text { (support area) } \\ 1+\text { intc }, & -0.5<\text { intc }<0 \text { (support area) } \\ 1+\text { intc }, & \text { int } c=-0.5 \quad \text { (neutral area) } \\ 1+\text { intc }, & -1 \leq \text { intc }<-0.5 \text { (opposition area) }\end{cases}$

The online version of the original article can be found under doi:10.1007/s41066-016-0026-1.

Xunwei Zhou

zhouxunwei@263.net

1 Institute of Information Technology, Beijing Union

University, Beijing, China 